\title{
Neurosurgical simulator for training aneurysm microsurgery-a user suitability study involving neurosurgeons and residents
}

\author{
Fredrick Johnson Joseph ${ }^{1} \cdot$ Stefan Weber ${ }^{1} \cdot$ Andreas Raabe $^{2} \cdot$ David Bervini $^{2}$ (D)
}

Received: 28 April 2020 / Accepted: 30 July 2020 / Published online: 11 August 2020

(C) The Author(s) 2020

\begin{abstract}
Background Due to its complexity and to existing treatment alternatives, exposure to intracranial aneurysm microsurgery at the time of neurosurgical residency is limited. The current state of the art includes training methods like assisting in surgeries, operating under supervision, and video training. These approaches are labor-intensive and difficult to fit into a timetable limited by the new work regulations. Existing virtual reality (VR)-based training modules lack patient-specific exercises and haptic properties and are thus inferior to hands-on training sessions and exposure to real surgical procedures.

Materials and methods We developed a physical simulator able to reproduce the experience of clipping an intracranial aneurysm based on a patient-specific 3D-printed model of the skull, brain, and arteries. The simulator is made of materials that not only imitate tissue properties including arterial wall patency, thickness, and elasticity but also able to recreate a pulsatile blood flow. A sample group of 25 neurosurgeons and residents ( $n=16$ : early residency with less than 4 years of neurosurgical exposure; $n=9$ : late residency and board-certified neurosurgeons, 4-15 years of neurosurgical exposure) took part to the study. Participants evaluated the simulator and were asked to answer questions about surgical simulation anatomy, realism, haptics, tactility, and general usage, scored on a 5-point Likert scale. In order to evaluate the feasibility of a future validation study on the role of the simulator in neurosurgical postgraduate training, an expert neurosurgeon assessed participants' clipping performance and a comparison between groups was done.

Results The proposed simulator is reliable and potentially useful for training neurosurgical residents and board-certified neurosurgeons. A large majority of participants ( $84 \%$ ) found it a better alternative than conventional neurosurgical training methods. Conclusion The integration of a new surgical simulator including blood circulation and pulsatility should be considered as part of the future armamentarium of postgraduate education aimed to ensure high training standards for current and future generations of neurosurgeons involved in intracranial aneurysm surgery.
\end{abstract}

Keywords Resident training $\cdot$ Surgical simulation $\cdot$ Surgical education $\cdot$ Microsurgery $\cdot$ Intracranial aneurysm $\cdot$ Neurosurgery

\section{Introduction}

Because of its complexity and the alternative treatments available, neurosurgery trainees today have limited exposure to microsurgery of intracranial aneurysms [1-3]. Exposure to aneurysm clipping usually occurs during the advanced phase

This article is part of the Topical Collection on Neurosurgery Training

David Bervini

david.bervini@insel.ch

1 ARTORG Center for Biomedical Engineering Research, University of Bern, Bern Switzerland

2 Department of Neurosurgery, Bern University Hospital and University of Bern, 3010 Bern Switzerland of a residency program or, for a select group, during a dedicated fellowship [4, 5]. The current state-of-the-art approaches are typically labor-intensive and difficult to fit into a time schedule depending on the work regulations. Other surgical disciplines have successfully implemented simulation tools and considered them as an effective training method [6,7]. However, existing neurosurgical training models, like static simulators and virtual reality (VR) training, do not provide a realistic experience and are hard to use for limited and complex surgical anatomy [8-12]. Intracranial aneurysm microsurgery is also difficult to practice on ex vivo models (human or animal specimens) because vascular pulsatility cannot yet be realistically replicated $[1,13-15]$. To successfully train neurosurgeons to operate under realistic conditions, a simulation tool should replicate the risk of aneurysm rupture, provide 
them with a realistic experience of microsurgical manipulation, and give them a thorough knowledge of the morphology of the brain and surrounding vascular structures $[3,11,16]$.

$3 \mathrm{D}$ aneurysm surgical simulators and physical models have been reported, but they lack blood-like flow time resolution and other crucial components like patency, dynamic behavior, haptics, tactility, and feedback for handling micro-surgical tools and clips $[2,17]$. Existing models to date cannot expose trainees to the entire surgical workflow, which includes indocyanine-green video angiography (ICG) for inspecting aneurysm occlusion $[18,19]$. Because the aneurysm wall and sac are very delicate, it is also difficult to mimic and simulate the sub-millimeter field $[20,21]$. Today's residents are more likely to learn through the conventional process, resulting in a global shortage of surgical exposure and making it difficult to train qualified cerebrovascular neurosurgeons [4].

Functional training simulators that replicate the required surgical anatomy and physiology could address this problem. In the last few years, manufacturing techniques have improved enough to produce true scale models of a patientspecific intracranial aneurysm, based on image data from real patients $[22,23]$. We have developed a bench-top simulator that meets this need for realistic neurosurgical training models with blood flow and pulsatility, an additional dimension.

Our goal was to assess the realism of the simulation model and determine if it is feasible to use the simulator to train residents and neurosurgeons in intracranial aneurysm microsurgery.

\section{Material and methods}

\section{Simulator and phantom}

Image datasets from a patient with a left 14-mm middle cerebral artery (MCA) bifurcation aneurysm were used, including various imaging modalities (e.g., digital subtraction angiography [DSA], computer tomography [CT], and magnetic resonance images [MRI]) for thresholding-based segmentation with Amira 6.3 (Thermo Fischer Scientific, MA, USA). No additional special techniques were employed. True scale hardtissue and soft-tissue portions of the required anatomy (skull, brain, intracranial arteries, and aneurysm) were $3 \mathrm{D}$ printed and produced according to standard additive manufacturing principles [24].

We selected materials that replicate human mechanical and haptic properties $[25,26]$. A standard left pterional craniotomy approach was made in the 3D-printed skull using Solidworks 2019 (Dassault Systems, France), as shown in Fig. 1a. The physical models, including the vascular anatomy, were positioned, assembled, and spatially oriented (Fig. 1b) using the image datasets and according to the patient's anatomy [27]. The replica of the left distal internal carotid artery was connected to a custom-designed pulsatile pump able to reproduce a patient's cardiac physiology (heart rate 50-110 BPM) and blood pressure (60-100/100-140 $\mathrm{mmHg}$ ). A software application controlled the pumping unit to vary the heart rate and pressure, but we kept them constant for the purposes of this study (heart rate $70 \mathrm{BPM}$; blood pressure $80 / 120 \mathrm{mmHg}$ ). The continuous, pulsatile blood circulation was connected to a reservoir, closing the loop. The blood flow emulates haptic and optical behavior when mixed with ICG dye (VERDYE $5 \mathrm{mg} / \mathrm{ml}$, Diagnostic Green GmbH, Germany).

The head model was placed and fixed with an adjustable 6degrees of freedom arm to properly position the head (flexion/ extension and rotation). The brain retractors were part of the simulator, but it was up to surgeons and participants to decide whether or not to use them. A neurosurgical microscope (OPMI ${ }^{\circledR}$ Pentero ${ }^{\circledR}$ 600, Carl Zeiss Surgical GmbH, Germany) was included in the bench-top training module.

\section{Study arrangements and participants}

This study included 25 neurosurgery residents and boardcertified neurosurgeons from several countries. Most participants had chosen cerebrovascular neurosurgery as their subspecialty focus (Table 1). To evaluate the quality of the training, we divided participants into two groups based on their surgical exposure and experience: group A included those in their early residency $(<4$ years of full training); group B included those in their late residency (at least 4 years of full training) and board-certified neurosurgeons. Of the 9 participants in group B, 3 had over 4-15 years of neurosurgical experience, had clipped 10-150 aneurysms, and had more advanced neurosurgical experience than the other participants. The other 6 participants in group B were less experienced or had never performed neurovascular surgeries without supervision. Group A included 16 doctors in early residency, of mixed experience levels that varied from a few months to almost 4 years. All 16 participants in group A had assisted or viewed neurovascular procedures like aneurysm clipping but none had clipped an aneurysm (Table 1).

Participants were provided with a 2D DICOM image dataset of the patient model in order to anticipate the vascular anatomy and the clipping strategy. Five copies of the head replica were available and ready to switch into the simulator if the aneurysm ruptured during training.

\section{Study design}

State-of-the-art microsurgical instruments, including intracranial aneurysm clips, manipulators, and dissectors, were available for the training. Participants viewed the mimicking pathology through a surgical microscope (OPMI ${ }^{\circledR}$ Pentero® 
Fig. 1 Representation of the model during the training study: a Patient-specific 3D-printed trephined skull with brain model. b MCA aneurysm model located in the left Sylvian fissure. c Pulsating blood vessel and access to the pathology of the model. d Brain retractor during manipulation by resident
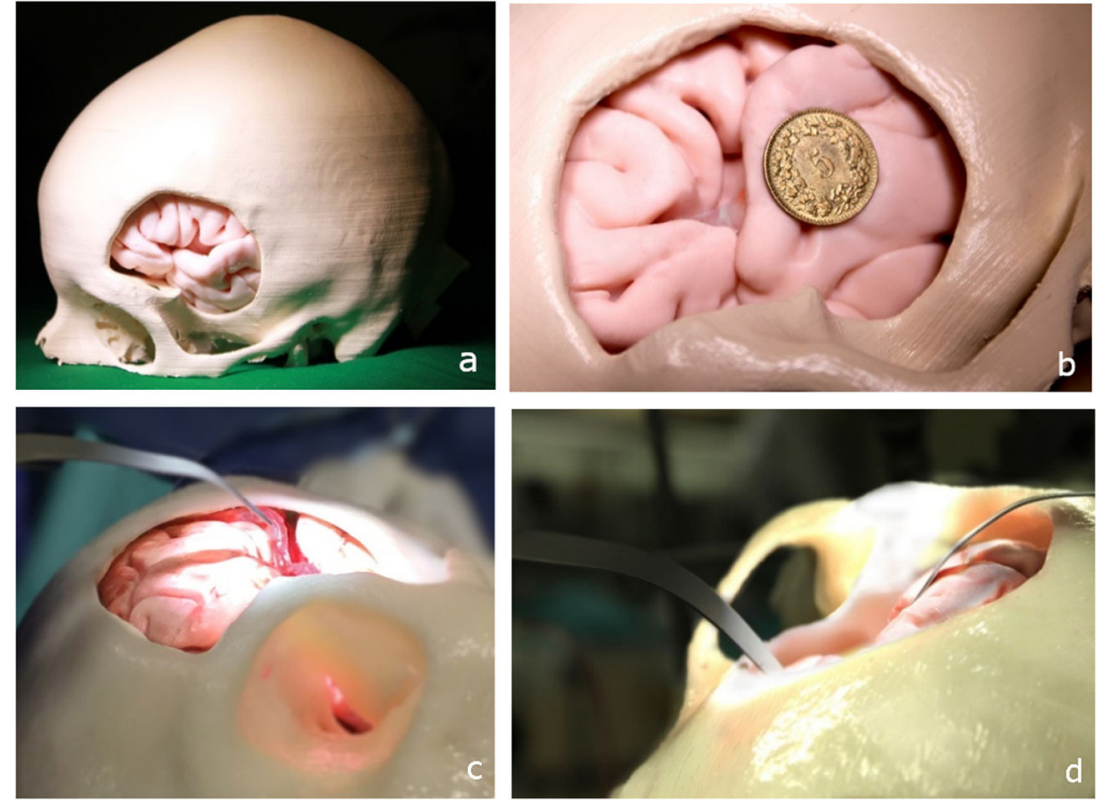

600, Carl Zeiss Surgical GmbH, Germany). They manipulated the vessel structures before they chose the correct clip configuration (Fig. 2). Participants were given only one attempt to clip. Blood-like pulsatility through the model was held constant for all participants. The clipping procedure was recorded under the microscope and used by a blinded fully trained cerebrovascular neurosurgeon (DB) to assess the quality of each participant's clipping after the training. The procedures were scored after reviewing ICG imaging (aneurysm obliteration: complete vs. incomplete) and assessing normal artery patency. Clipping results fell into one of three categories: (a) successful clipping (complete aneurysm occlusion, normal artery patency); (b) partial clipping (if clipping resulted in only partial aneurysm occlusion and normal artery patency); and (c) failed to clip/unsuccessful clipping ((1) could not attempt clipping, (2) aneurysm sac unsuccessfully occluded, (3) normal artery patency compromised, (4) aneurysm rupture). After a participant had clipped the aneurysm and marked the attempt as complete, she or he was asked to complete the study questionnaires (Table 2).

\section{Survey instrument development and administration}

Attitudinal questions were formatted as 5-point Likert scales (Table 2). Some questions were multiple-choice questions to provide insight into the ease of use of this new training approach. Study data were collected and managed in REDCap 9.7.8 (Research Electronic Data Capture, Vanderbilt University) electronic data capture tools, hosted at ARTORG Center, Switzerland [28, 29].

\section{Statistical analysis and study outcomes}

Survey responses were coded and double-checked for accuracy. Survey data was statistically analyzed with descriptive statistics for different endpoints with dedicated software (R Studio 1.2.5 Programming, 2020). The primary aim of the study was to determine if it is possible to use the simulator to train residents and neurosurgeons. We compared the clipping performance of each study group to find out if we could use the simulator to conduct a

Table 1 Overview of participants and background

\begin{tabular}{|c|c|c|c|c|c|}
\hline \multirow{3}{*}{$\begin{array}{l}\text { Years of neurosurgical experience } \\
\text { No. of participants in each group }\end{array}$} & \multicolumn{5}{|c|}{ No. of participants $n=25$} \\
\hline & \multirow{2}{*}{$\begin{array}{l}\text { Group A: }<4 \text { years } \\
\text { Early residency } \\
16\end{array}$} & \multicolumn{4}{|c|}{$\begin{array}{l}\text { Group B: 4-15 years } \\
\text { Late-residency and board-certified neurosurgeons }\end{array}$} \\
\hline & & 2 & 2 & 2 & 3 \\
\hline Background & Neurosurgery-resident & $\begin{array}{l}\text { Functional } \\
\text { neurosurgery }\end{array}$ & $\begin{array}{l}\text { Pediatrics and } \\
\text { tumor }\end{array}$ & $\begin{array}{l}\text { Vascular } \\
\text { neurosurgery }\end{array}$ & $\begin{array}{l}\text { Vascular } \\
\text { neurosurgery }\end{array}$ \\
\hline $\begin{array}{l}\text { No. of aneurysm clipped as the main } \\
\text { surgeon }\end{array}$ & 0 & 0 & & & $10-150$ \\
\hline
\end{tabular}


Fig. 2 Pictorial representation from the simulator and study participation: a Expert neurovascular surgeon manipulating the aneurysm model in the simulator and trying to clip. b Young resident neurosurgeon clipping. c Attempt to clipping. d Exploration after clipping
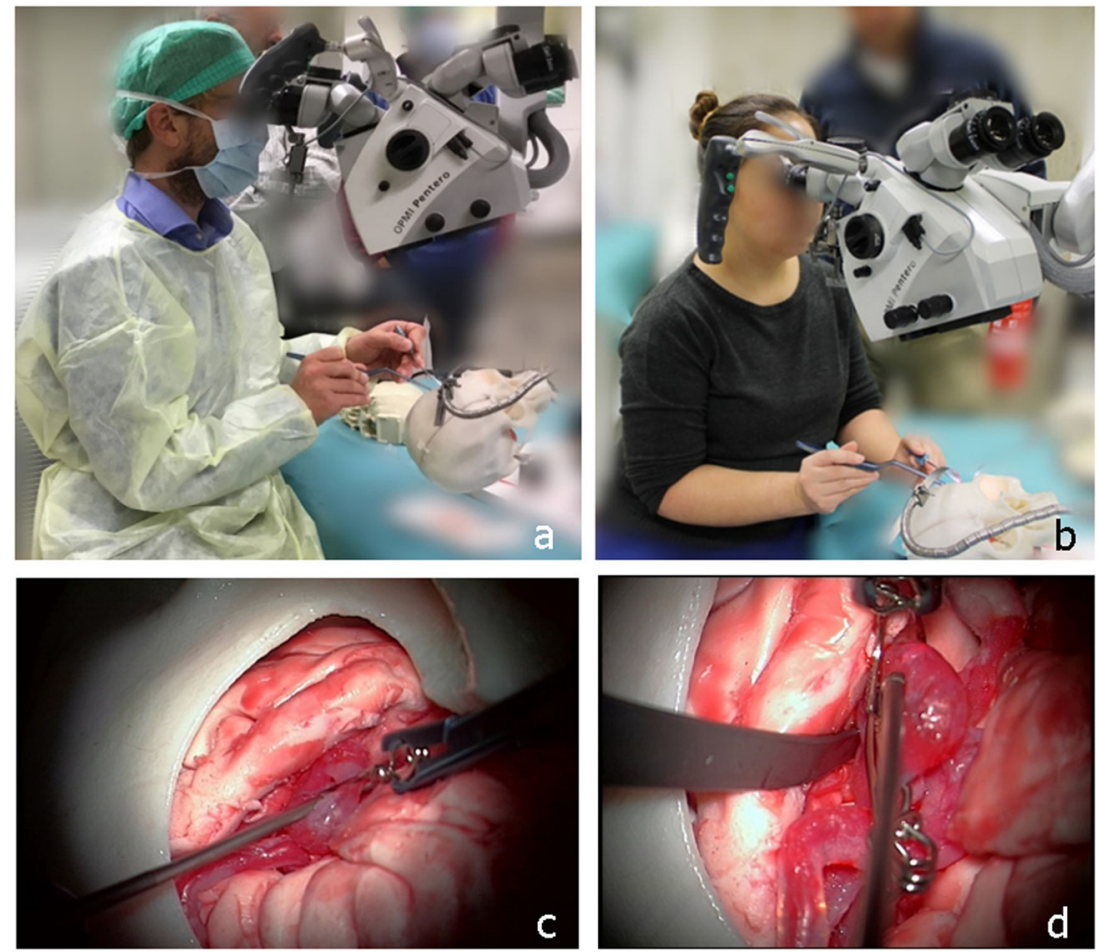

validation study that would measure the learning curve of residents as they train with the simulator.

\section{Results}

\section{Surgical anatomy simulation}

Participants were asked eight questions about simulation anatomy to determine how closely the simulation models emulated reality and to compare the effectiveness of training with the simulator with that of the theoretical learning process. Many respondents scored the benefits of the model in a range differing from helpful to same as of theoretical learning. A large majority $(84 \% ; n=21)$ found that the simulator improved their understanding of microvascular structures and anatomy far more than theoretical learning. A similar number $(88 \% ; n=$ 22 ) found that the simulator was of great help in preparing them for surgery. Most $(80 \% ; n=20)$ found the simulator very useful for teaching them the neighboring anatomy and the same number $(80 \% ; n=20)$ found that the simulator helped them learn the morphology of the surgical field so they could differentiate the surrounding anatomy from the pathology. Most participants $(88 \% ; n=22)$ thought this novel training method improved their understanding of surgery and was more useful than theoretical learning for the understanding of flow patency during aneurysm clipping. Most participants ( $84 \% ; n=24$ ) found the clipping simulation to be as realistic as surgery and all participants felt that the global visual appearance of the model was realistic. Differences in their responses to the simulation anatomy are shown in Fig. 3. Figure 4 shows the responses on general usability feedback and future use areas of the simulator.

\section{Haptics, tactile feedback, and clipping similarity}

Three questions on haptics, tactility, and clipping similarity were asked only of group B (late residency and board-certified neurosurgeons) in order to assess the unique features of the simulator. Almost all group B members (89\%; $n=8 / 9)$ felt that the model's tactility while clipping was realistic. The same number found the haptics realistic, and most $(78 \% ; n=7)$ found that the simulation resembled real clipping surgery (Fig. 5).

\section{Status of clipping nature}

A comparison of clipping performance between group A (early residency) and group B (late residency and board-certified neurosurgeons) is shown in Fig. 6. In group A, 12 out of 16 failed to clip, 3 partially clipped, and 1 clipped the aneurysm successfully. In group B, 2 out of 9 failed to clip, 3 partially closed the aneurysm, and 4 clipped successfully.

\section{Discussion}

During surgery, neurosurgeons must be judgmental when choosing the matching clip(s) arrangement to completely occlude the 
Table 2 List of questionnaire

\section{Micro Neurosurgical Intracranial Aneurysm Simulator- Questionnaire}

1. Background / Specialization

2. Years of Experience

3. Number of aneurysms clipped or treated (Approximately)

\begin{tabular}{|c|c|c|c|c|c|c|}
\hline \multicolumn{7}{|c|}{ Simulator- Surgical Anatomy } \\
\hline & & Helps a Lot & Helps & Moderate & Not Helpful & Same as Theoretical Learning \\
\hline 4. & Understanding the Vascular structure & $\mathrm{O}$ & $\mathrm{O}$ & $\mathrm{O}$ & $\mathrm{O}$ & 0 \\
\hline 5. & Helps in preparing for surgery & $\mathrm{O}$ & $\mathrm{O}$ & $\mathrm{O}$ & $\mathrm{O}$ & $\mathrm{O}$ \\
\hline 6. & $\begin{array}{l}\text { Realizing spatial relation with respect to the nearby surgical } \\
\text { field }\end{array}$ & $\mathrm{O}$ & $\mathrm{O}$ & $\mathrm{O}$ & $\mathrm{O}$ & $\mathrm{O}$ \\
\hline 7. & Did it improve your understanding of the surgical view? & $\mathrm{O}$ & $\mathrm{O}$ & $\mathrm{O}$ & $\mathrm{O}$ & $\mathrm{O}$ \\
\hline 8. & Understanding the morphology of the field & $\mathrm{O}$ & $\mathrm{O}$ & $\mathrm{O}$ & $\mathrm{O}$ & $\mathrm{O}$ \\
\hline \multirow[t]{2}{*}{9.} & Patency and gathering idea in Clipping & $\mathrm{O}$ & $\mathrm{O}$ & $\mathrm{O}$ & $\mathrm{O}$ & $\mathrm{O}$ \\
\hline & & Amazing & Good" & Moderate & Not Bad & $\begin{array}{l}\text { No Visual Appeal/ } \\
\text { Not required }\end{array}$ \\
\hline 10. & Visual Appearance & $\mathrm{O}$ & $\mathrm{O}$ & $\mathrm{O}$ & $\mathrm{O}$ & $\mathrm{O}$ \\
\hline 11. & Realism of Simulation & $\mathrm{O}$ & $\mathrm{O}$ & $\mathrm{O}$ & $\mathrm{O}$ & $\mathrm{O}$ \\
\hline \multicolumn{7}{|c|}{ Simulator- Usage Feedback } \\
\hline & & $\begin{array}{l}\text { Helpful and Very } \\
\text { much required }\end{array}$ & $\begin{array}{l}\text { Helpful } \\
\text { and required }\end{array}$ & Required & Not Sure & $\begin{array}{l}\text { Not Helpful and } \\
\text { Not Required }\end{array}$ \\
\hline 12. & $\begin{array}{l}\text { Patient Illustration (Model ready with trephined Skull and your } \\
\text { opinion) }\end{array}$ & $\mathrm{O}$ & $\mathrm{O}$ & $\mathrm{O}$ & $\mathrm{O}$ & $\mathrm{O}$ \\
\hline 13. & Teaching & $\mathrm{O}$ & $\mathrm{O}$ & $\mathrm{O}$ & $\mathrm{O}$ & $\mathrm{O}$ \\
\hline 14. & Medical Education & $\mathrm{O}$ & $\mathrm{O}$ & $\mathrm{O}$ & $\mathrm{O}$ & $\mathrm{O}$ \\
\hline 15. & Surgical Training & $\mathrm{O}$ & $\mathrm{O}$ & $\mathrm{O}$ & $\mathrm{O}$ & $\mathrm{O}$ \\
\hline 16. & Preoperative Planning & $\mathrm{O}$ & $\mathrm{O}$ & $\mathrm{O}$ & $\mathrm{O}$ & $\mathrm{O}$ \\
\hline 17. & Ease of manipulating neck with pulsation & $\mathrm{O}$ & $\mathrm{O}$ & $\mathrm{O}$ & $\mathrm{O}$ & $\mathrm{O}$ \\
\hline \multicolumn{7}{|c|}{ Simulator- Tactility, Haptics and Clipping Similarity } \\
\hline & & Very Realistic & Realistic & $\begin{array}{l}\text { Soft but } \\
\text { Not Realistic }\end{array}$ & Quite Hard & Hard \\
\hline \multirow[t]{2}{*}{18.} & Feeling the Intracranial Aneurysm or sense of touch (Tactility) & $\mathrm{O}$ & O & $\mathrm{O}$ & $\mathrm{O}$ & $\mathrm{O}$ \\
\hline & & $\begin{array}{l}\text { Excellent } \\
\text { Haptics }\end{array}$ & $\begin{array}{l}\text { Good } \\
\text { Haptics }\end{array}$ & Moderate & $\begin{array}{l}\text { OK, but can } \\
\text { be improved }\end{array}$ & No Haptics feeling \\
\hline \multirow[t]{2}{*}{19.} & Help in preparing for surgery (Haptics) & $\mathrm{O}$ & $\mathrm{O}$ & $\mathrm{O}$ & $\mathrm{O}$ & $\mathrm{O}$ \\
\hline & & $\begin{array}{l}\text { Highly } \\
\text { Similar to } \\
\text { real } \\
\text { clipping }\end{array}$ & Similar & Moderate & $\begin{array}{l}\text { Something is } \\
\text { missing }\end{array}$ & Not Known \\
\hline \multirow[t]{2}{*}{20.} & Did the clipping application seem realistic? (Similarity) & $\mathrm{O}$ & $\mathrm{O}$ & $\mathrm{O}$ & $\mathrm{O}$ & $\mathrm{O}$ \\
\hline & \multicolumn{5}{|c|}{ Yes, Definitely/ and I recommend for others } & No, I don't recommend \\
\hline 21. & $\begin{array}{l}\text { Do you think surgical skill improves by training in such } \\
\text { simulators? }\end{array}$ & $\mathrm{O}$ & & & & $\mathrm{O}$ \\
\hline 22. & Would you use the simulator? & $\mathrm{O}$ & & & & $\mathrm{O}$ \\
\hline
\end{tabular}

\section{More Suitable Training Method}
O Aneurysm Simulator
O Virtual Reality
O Augmented Reality
O Conventional method

24. Which improves your level of education/understanding?
O Aneurysm Simulator
O CT / MRI Patient Data
O Graphical Visualization

25. I would like to use the simulator in other areas like

O Research $\quad$ Education and Training O Improving my skills during regular clinical $\quad \begin{gathered}0 \text { I would like to continue using the simulator for } \\ \text { practice/ Patient-Specific Training procedure or once in a few weeks }\end{gathered}$

26. Successfully Clipped (Reviewed by Expert)

O Successfully clipped O Partially Clipped O Unsuccessful clipping 
Fig. 3 Likeability scoringneurosurgical simulation anatomy

\begin{tabular}{|c|c|c|c|c|c|c|c|}
\hline \multicolumn{8}{|c|}{ Simulator-Surgical Anatomy } \\
\hline \multirow{2}{*}{\multicolumn{2}{|c|}{ Questions }} & \multirow{3}{*}{$\begin{array}{l}\text { Mean } \\
4.76\end{array}$} & \multicolumn{5}{|c|}{ Percentage (Number of Participants) } \\
\hline & & & $\begin{array}{c}\text { Same as } \\
\text { Theoretical } \\
\text { Learning }\end{array}$ & Not Helpful & Moderate & Helps & Helps a Lot \\
\hline 4. & $\begin{array}{l}\text { Understanding the Vascular } \\
\text { structure }\end{array}$ & & $0.0 \%(0)$ & $0.0 \%(0)$ & $8.0 \%(2)$ & $8.0 \%(2)$ & $84.0 \%(21)$ \\
\hline 5. & Helps in preparing for surgery & 4.83 & $0.0 \%(0)$ & $0.0 \%(0)$ & $4.0 \%(1)$ & $8.0 \%(2)$ & $88.0 \%(22)$ \\
\hline 6. & $\begin{array}{l}\text { Realizing spatial relation with } \\
\text { respect to the nearby surgical field }\end{array}$ & 4.76 & $0.0 \%(0)$ & $0.0 \%(0)$ & $4.0 \%(1)$ & $16.0 \%(4)$ & $80.0 \%(20)$ \\
\hline 7. & $\begin{array}{l}\text { Did it improve your understanding } \\
\text { of the surgical view? }\end{array}$ & 4.88 & $0.0 \%(0)$ & $0.0 \%(0)$ & $0.0 \%(0)$ & $12.0 \%(3)$ & $88.0 \%(22)$ \\
\hline 8. & Understanding the morphology & 4.80 & $0.0 \%(0)$ & $0.0 \%(0)$ & $0.0 \%(0)$ & $20.0 \%(5)$ & $80.0 \%(20)$ \\
\hline 9. & $\begin{array}{l}\text { Patency and gathering idea in } \\
\text { Clipping }\end{array}$ & 4.88 & $0.0 \%(0)$ & $0.0 \%(0)$ & $0.0 \%(0)$ & $12.0 \%(3)$ & $88.0 \%(22)$ \\
\hline 10. & \multicolumn{2}{|l|}{ Visual Appearance } & \multicolumn{4}{|l|}{$0 \%(0)$} & $100 \%(25)$ \\
\hline 11. & \multicolumn{2}{|l|}{ Realism of 4D Simulation } & \multicolumn{4}{|l|}{$16 \%(4)$} & $84 \%(21)$ \\
\hline \multicolumn{8}{|c|}{$\square$ Not Required $\square$ Not Bad $\square$ Moderate $\square$ Good $\square$ Amazing } \\
\hline
\end{tabular}

intracranial aneurysm. Proven aneurysm remnant after clipping is reported in the literature to be as high as $14 \%$ [30], while surgical manipulation and aneurysm clipping put adjacent vessels at risk for stenosis, occlusion, or insult, this being potentially responsible for brain ischemia and infarction [31-34].

Cerebrovascular neurosurgery is and will always be motivated by technical skills, and the operating room is becoming an increasingly difficult environment for residents to obtain these skills. Residency work hour restrictions, the need to perform research, the increase in patient complexity, and the proliferation of alternative procedures have resulted in a reduction in hands-on operative learning opportunities and a change of required competencies. Several simulation training platforms are available for many medical disciplines and in a variety of forms like ex vivo models (cadaveric and animal), virtual reality handling, and static $3 \mathrm{D}$ anatomical demonstrators. Simulation training allows deliberate practice, progressive operative responsibility, and coaching by a senior surgeon. Simulators have been used to improve the performance of trainees in many areas of surgery and there is a growing demand for technological development in this area. Multiple studies have consistently demonstrated that the use of simulators improves qualitative and quantitative performance measures as well as overall resident and surgeon confidence in clinical settings. [35-38]

Although simulated training methods for practicing invasive procedures have been made available in other surgical specialties, realistic simulation options in cerebrovascular neurosurgery, including aneurysm clipping, are scanty. In neurosurgery, training modules reported so far have been missing blood-like flow time resolution (pulsatility) and other crucial phenomena like vascular patency, dynamic behavior, haptics, tactility, and the feedback of handling micro-surgical tools or to deal with intraoperative hemorrhage. This makes the surgeons unexposed to the complete surgical workflow. These aspects, together with the procedure-related morbidity, raise the need for functional, more realistic training simulators replicating the required surgical anatomy and physiology.
Fig. 45 Likert scale score on the usefulness of the simulator about a different area of applications

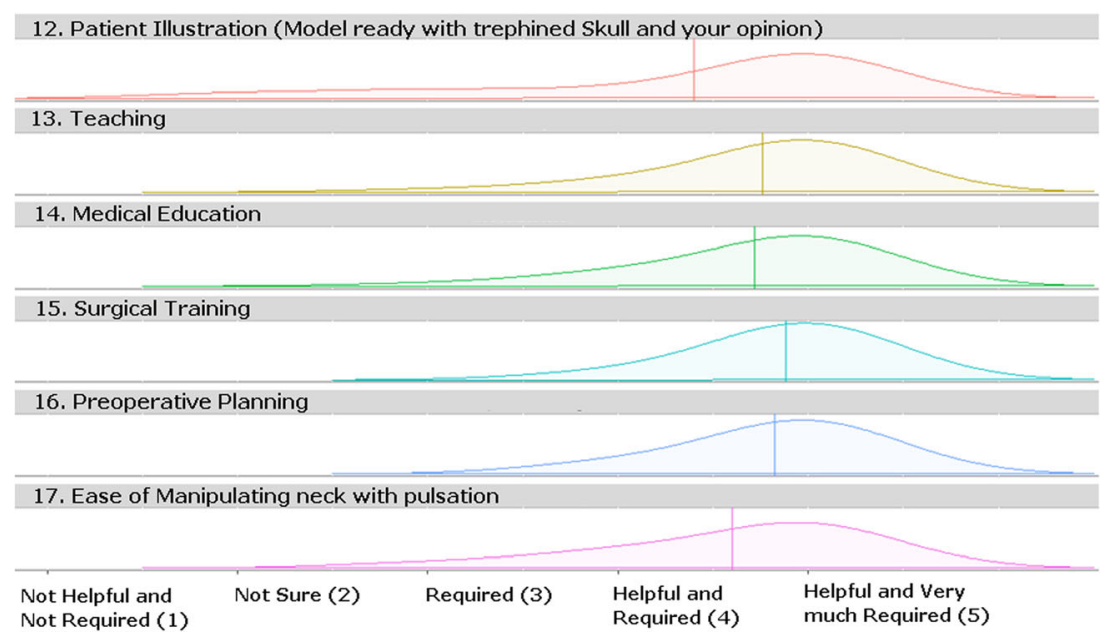


Fig. 5 Likert user rating on the simulation training evaluating the tactile, haptics, and clipping similarity during the training process

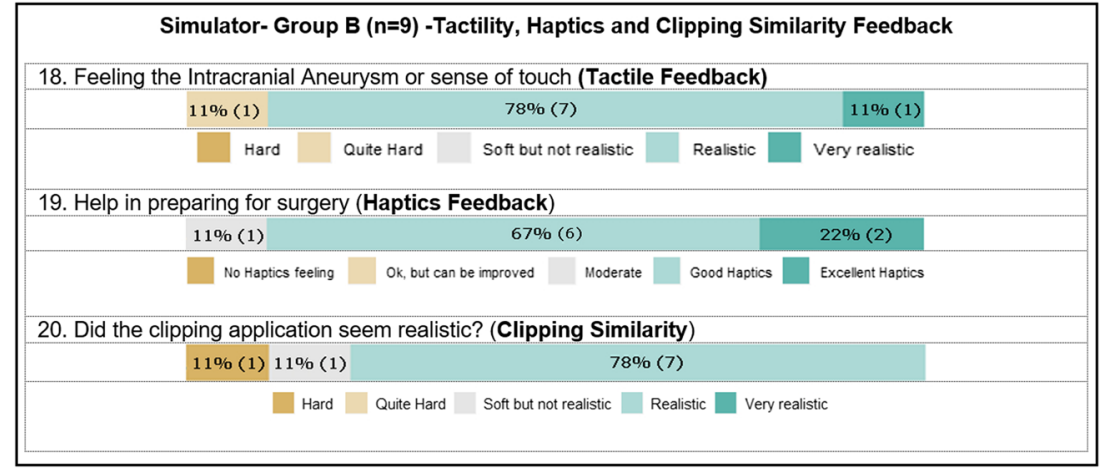

The recent development of additive manufacturing techniques leads us to develop a true scale, patient-specific bench-top simulator prototype.

The present study showed that more than $80 \%$ of the participants felt that our new anatomy simulation was a good alternative to theoretical and conventional learning [39]. All participants found the visual aspects of the simulation appealing, while most participants found the anatomical environment and the tactile and haptic aspects of the pathology in the simulation to be realistic. Participants' responses to the multiple-choice questions indicated that over $80 \%$ were willing to use the simulator for education and training purposes. The same number felt that the simulator could be useful for patient-specific preoperative training in regular clinical practice and agreed that it would possibly improve their surgical skills.

The comparison of clipping performance between the groups showed, as intuitively expected, that trainees in their early stages of residency potentially need a long exposure to the simulator to improve their microsurgery clipping skills. In

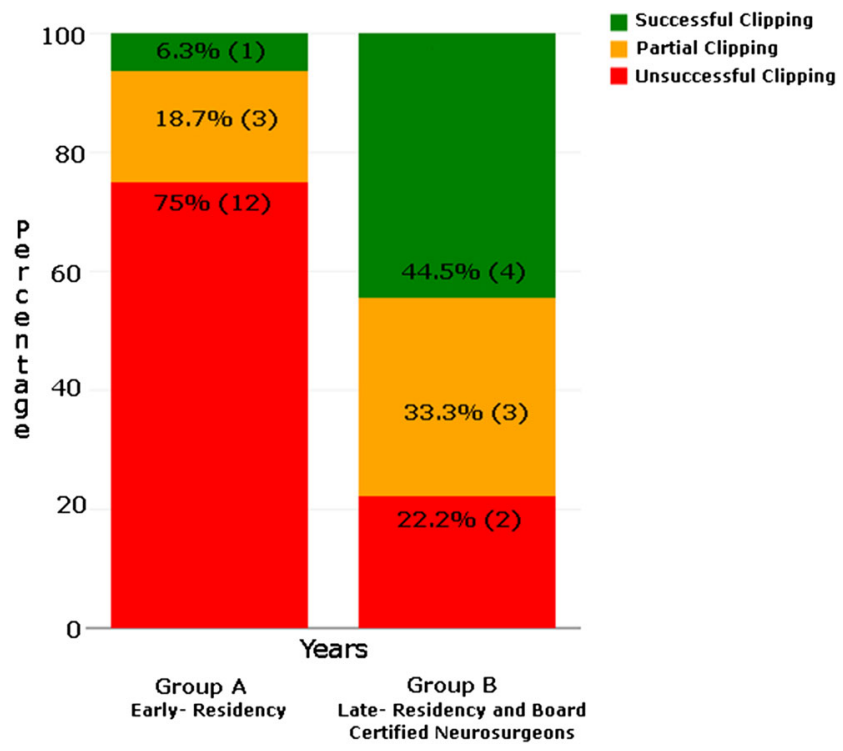

Fig. 6 Nature of clipping (successful, unsuccessful, and partially done) vs. years of experience between group A and group B participants group B (late residency and board-certified neurosurgeons), 2 of the 9 participants also failed, perhaps because their exposure to this type of surgical procedure was limited, and perhaps because of the anatomy of the aneurysm we selected for this study was particularly challenging. This underlines the need for a validation study aiming to measure the learning curve of residents as they train with the simulator.

\section{Limitations and future directions}

Despite our effort to reproduce the skull, brain, and vascular anatomy, further anatomic elements like the skin, galea, meninges, veins, and arachnoid were missing. This did not allow the complete surgical workflow to be reproduced.

Our study design and data did not allow us to compare the effectiveness of training. Future studies should focus on collecting long-term follow-up data and quantified parameters on simulated outcomes. This would allow us to measure the performance capacity and to establish a learning curve in order to determine whether there is an advantage to training in the simulated environment. To date, neurosurgeons have been using only one indicator of performance: patient outcomes. Our simulator could incorporate alternative measures to improve and maintain skills.

Further studies are needed in order to confirm that the present simulator is a valuable clinical tool for measuring, evaluating, and maintaining quality assurance in the training and education of future generations of neurosurgeons. These studies should include an assessment of the learning curve and skills improvement over time, with the goal of ensuring a high level of post-graduate education and patient care.

\section{Conclusion}

The integration of a new surgical simulator including blood circulation and pulsatility should be considered as part of the future armamentarium of postgraduate education aimed to ensure high training standards for current and future generations of neurosurgeons involved in intracranial aneurysm surgery. 
Acknowledgment The authors would like to thank the members of the image-guided therapy group, ARTORG Center, and the Department of Neurosurgery, Inselspital, Bern, Switzerland, for their support.

Funding information Open Access funding provided by University of Bern.

\section{Compliance with ethical standards}

Ethical approval disclosure This study was approved by the Ethics committee in the State of Bern, under the approval number KEK Bern-201901335 .

Conflict of interest The authors declare that they have no conflict of interest.

Open Access This article is licensed under a Creative Commons Attribution 4.0 International License, which permits use, sharing, adaptation, distribution and reproduction in any medium or format, as long as you give appropriate credit to the original author(s) and the source, provide a link to the Creative Commons licence, and indicate if changes were made. The images or other third party material in this article are included in the article's Creative Commons licence, unless indicated otherwise in a credit line to the material. If material is not included in the article's Creative Commons licence and your intended use is not permitted by statutory regulation or exceeds the permitted use, you will need to obtain permission directly from the copyright holder. To view a copy of this licence, visit http://creativecommons.org/licenses/by/4.0/.

\section{References}

1. Belykh EG, Byval'tsev VA, Nakadzhi P, Lei T, Oliviero MM, Nikiforov SB (2014) [A model of the arterial aneurysm of the brain for microneurosurgical training]. Zh Vopr Neirokhir Im N N Burdenko 78(2):40-5- discussion 45

2. Kang Y, Yu L-H, Xu T, Zheng S-F, Yao P-S, Liu M, Lin Y-X, Lin Z-Y, Fan X-M, Kang D-Z (2016) Three-dimensional printing technology for treatment of intracranial aneurysm. Chin Neurosurg J1 2(1):1-10

3. Vakharia VN, Vakharia NN, Hill CS (2016) Review of 3dimensional printing on cranial neurosurgery simulation training. World Neurosurg 88:188-198

4. Dewan MC, Rattani A, Fieggen G, Arraez MA, Servadei F, Boop FA, Johnson WD, Warf BC, Park KB (2018) Global neurosurgery: the current capacity and deficit in the provision of essential neurosurgical care. Executive Summary of the Global Neurosurgery Initiative at the Program in Global Surgery and Social Change. J Neurosurg 130(4):1055-1064

5. Kirkman MA, Ahmed M, Albert AF, Wilson MH, Nandi D, Sevdalis N (2014) The use of simulation in neurosurgical education and training. A systematic review. J Neurosurg 121(2):228-246

6. Lim PK, Stephenson GS, Keown TW, Byrne C, Lin CC, Marecek GS, Scolaro JA (2018) Use of 3D printed models in resident education for the classification of acetabulum fractures. Journal of Surgical Education 75(6):1679-1684

7. Williams A, McWilliam M, Ahlin J, Davidson J, Quantz MA, Bütter A (2018) A simulated training model for laparoscopic pyloromyotomy: Is $3 \mathrm{D}$ printing the way of the future? J Pediatr Surg 53(5):937-941

8. Alaraj A, Luciano CJ, Bailey DP, Elsenousi A, Roitberg BZ, Bernardo A, Banerjee PP, Charbel FT (2015) Virtual reality cerebral aneurysm clipping simulation with real-time haptic feedback. Neurosurgery 1-7

9. Beier F, Sismanidis E, Stadie A, Schmieder K, Männer R (2012) An aneurysm clipping training module for the neurosurgical training simulator NeuroSim. Stud Health Technol Inform 173:42-47

10. Craven C, Baxter D, Cooke M, Carline L, Alberti SJMM, Beard J, Murphy M (2014) Development of a modelled anatomical replica for training young neurosurgeons. Br J Neurosurg 28(6):707-712

11. Koyama T, Hongo K, Tanaka Y, Kobayashi S (2000) Simulation of the surgical manipulation involved in clipping a basilar artery aneurysm: concepts of virtual clipping: Technical note. J Neurosurg 93(2):355-360

12. Kumagai K, Mori K, Takeuchi S, Wada K (2019) Surgical training for the management of intraoperative aneurysm rupture using a three-dimensional artificial model. Asian Journal of Neurosurgery 14(1):172-174

13. Benet A, Plata-Bello J, Abla AA, Acevedo-Bolton G, Saloner D, Lawton MT (2015) Implantation of 3D-printed patient-specific aneurysm models into cadaveric specimens: a new training paradigm to allow for improvements in cerebrovascular surgery and research. BioMed Research International 2015(4):1-9

14. Waran V, Narayanan V, Karuppiah R, Pancharatnam D, Chandran H, Raman R, Rahman ZAA, Owen SLF, Aziz TZ (2014) Injecting realism in surgical training-initial simulation experience with custom 3D models. Journal of Surgical Education 71(2):193-197

15. Waran V, Narayanan V, Karuppiah R, Thambynayagam HC, Muthusamy KA, Rahman ZAA, Kirollos RW (2015) Neurosurgical endoscopic training via a realistic 3-dimensional model with pathology. Simul Healthc 10(1):43-48

16. Leal A, Souza M, Nohama P (2019) Additive manufacturing of 3D biomodels as adjuvant in intracranial aneurysm clipping. Artif Organs 43(1):E9-E15

17. Kimura T, Morita A, Nishimura K, Aiyama H, Itoh H, Fukaya S, Sora S, Ochiai C (2009) Simulation of and training for cerebral aneurysm clipping with 3-dimensional models. Neurosurgery 65(4):719-25- discussion 725-6

18. Liu Y, Ghassemi P, Depkon A, Iacono MI, Lin J, Mendoza G, Wang J, Tang Q, Chen Y, Pfefer TJ (2018) Biomimetic 3Dprinted neurovascular phantoms for near-infrared fluorescence imaging. Biomed Opt Express 9(6):2810-2824

19. Raabe A, Nakaji P, Beck J, Kim LJ, Hsu FPK, Kamerman JD, Seifert V, Spetzler RF (2005) Prospective evaluation of surgical microscope-integrated intraoperative near-infrared indocyanine green videoangiography during aneurysm surgery. J Neurosurg 103(6):982-989

20. Mashiko T, Otani K, Kawano R, Konno T, Kaneko N, Ito Y, Watanabe E (2015) Development of three-dimensional hollow elastic model for cerebral aneurysm clipping simulation enabling rapid and low cost prototyping. WNEU 83(3):351-361

21. Wurm G, Lehner M, Tomancok B, Kleiser R, Nussbaumer K (2011) Cerebrovascular biomodeling for aneurysm surgery: simulation-based training by means of rapid prototyping technologies. Surg Innov 18(3):294-306

22. Kaneko N, Mashiko T, Namba K, Tateshima S, Watanabe E, Kawai K (2018) A patient-specific intracranial aneurysm model with endothelial lining: a novel in vitro approach to bridge the gap between biology and flow dynamics. J NeuroIntervent Surg 10(3):306-309

23. Scerrati A, Trovalusci F, Albanese A, Ponticelli GS, Tagliaferri V, Sturiale CL, Cavallo MA, Marchese E (2019) A workflow to generate physical 3D models of cerebral aneurysms applying open source freeware for CAD modeling and 3D printing. Interdisciplinary Neurosurgery 17:1-6

24. Joseph FJ, Bervini D, Raabe A, Weber S (2019) Production of intracranial dynamic aneurysm models for neurosurgical applications and future directions. Joseph, Fredrick Johnson; Bervini, 
David; Raabe, Andreas; Weber, Stefan (19 September 2019) Production of intracranial dynamic aneurysm models for neurosurgical applications and future directions In: 18 Jahrestagung der Deutschen Gesellschaft für Computer- und Roboterassistierte Chirurgie (pp 108-111) CURAC 2019. doi: https://doi.org/10. 7892/boris. 134185

25. Kaneko N, Mashiko T, Ohnishi T, Ohta M, Namba K, Watanabe E, Kawai K (2016) Manufacture of patient-specific vascular replicas for endovascular simulation using fast, low-cost method. Scientific Reports 2018 8:1 6(1):39168-39167

26. Ryan JR, Almefty KK, Nakaji P, Frakes DH (2016) Cerebral aneurysm clipping surgery simulation using patient-specific $3 \mathrm{D}$ printing and silicone casting. World Neurosurg 88:175-181

27. Luo M, Frisken SF, Weis JA, Clements LW, Unadkat P, Thompson RC, Golby AJ, Miga MI (2017) Retrospective study comparing model-based deformation correction to intraoperative magnetic resonance imaging for image-guided neurosurgery. J Med Imaging (Bellingham) 4(3):035003

28. Harris PA, Taylor R, Minor BL et al (2019) The REDCap consortium: building an international community of software platform partners. Journal of Biomedical Informatics 95:103208

29. Harris PA, Taylor R, Thielke R, Payne J, Gonzalez N, Conde JG (2009) Research electronic data capture (REDCap) - a metadatadriven methodology and workflow process for providing translational research informatics support. Journal of Biomedical Informatics 42(2):377-381

30. Sindou M, Acevedo JC, Turjman F (1998) Aneurysmal remnants after microsurgical clipping: classification and results from a prospective angiographic study (in a consecutive series of 305 operated intracranial aneurysms). Acta Neurochir (Wien) 140(11):11531159

31. Bekelis K, Missios S, MacKenzie TA, Desai A, Fischer A, Labropoulos N, Roberts DW (2014) Predicting inpatient complications from cerebral aneurysm clipping: the Nationwide Inpatient Sample 2005-2009. J Neurosurg 120(3):591-598
32. Bruneau M, Amin-Hanjani S, Koroknay-Pal P et al (2016) Surgical clipping of very small unruptured intracranial aneurysms. Neurosurgery 78(1):47-52

33. Bulters DO, Santarius T, Chia HL, Parker RA, Trivedi R, Kirkpatrick PJ, Kirollos RW (2010) Causes of neurological deficits following clipping of 200 consecutive ruptured aneurysms in patients with good-grade aneurysmal subarachnoid haemorrhage. Acta Neurochir (Wien) 153(2):295-303

34. Le Roux PD, Elliott JP, Eskridge JM, Cohen W, Winn HR (1998) Risks and benefits of diagnostic angiography after aneurysm surgery: a retrospective analysis of 597 studies. Neurosurgery 42(6): 1248-1254

35. Clark AD, Barone DG, Candy N, Guilfoyle M, Budohoski K, Hofmann R, Santarius T, Kirollos R, Trivedi RA (2017) The effect of 3-dimensional simulation on neurosurgical skill acquisition and surgical performance_a review of the literature. Journal of Surgical Education 74(5):828-836

36. Flemming B, Skou TAS, Joy NL, Lars K (2020) Surgical simulation: current practices and future perspectives for technical skills training. Medical Teacher 40(7):668-675

37. Johnston MJ, Paige JT, Aggarwal R, Stefanidis D, Tsuda S, Khajuria A, Arora S (2016) An overview of research priorities in surgical simulation: what the literature shows has been achieved during the 21 st century and what remains. The American Journal of Surgery 211(1):214-225

38. Yanagawa B, Ribeiro R, Naqib F, Fann J, Verma S, Puskas JD (2019) See one, simulate many, do one, teach one. Current Opinion in Cardiology 34(5):571-577

39. de Oliveira MMR, Ferrarez CE, Ramos TM et al (2018) Learning brain aneurysm microsurgical skills in a human placenta model: predictive validity. J Neurosurg 128(3):846-852

Publisher's note Springer Nature remains neutral with regard to jurisdictional claims in published maps and institutional affiliations. 